\title{
What future for Japan's universities?
}

\begin{abstract}
Japan's universities are still urgently in need of the autonomy that would enable them to reform themselves; the ministry in charge of them should embrace that as its goal.
\end{abstract}

THE enviable social stability of Japan rests on the general confidence that there are rarely abrupt changes. Earthquakes apart, continuity over the decades is a goal in its own right. And it is seriously impolite to make a bargain with a person only to go back on it afterwards, as for example by changing the terms of a person's employment. Those are some of the reasons for the paradox that the national universities of what is arguably the richest and certainly the most productive country in the world are now so urgently in need of change. Last week's Nature conference in Tokyo (see page 721) uncovered the case for reform at the end of two days, perhaps because the Japanese could no longer bear the frustration of learning of the dynamic (if somewhat breathless) changes afoot among their neighbours in the Pacific. What is now required?

Elsewhere, it would seem simple. The ministry (called Monbusho) that covers running costs should not also be the chief source of academic research support. As everywhere else, Japan needs an independent research council operating strictly by independent judgements of which research deserves support. Then Japan's national universities need administrative autonomy, with the right to run their own academic businesses (and occasionally to make mistakes in doing so). They also need means of forcing coherence on their own faculties, winning consensus on common goals even from those who now interpret academic freedom as a licence to follow solitary aims (or none), and the habit of exposing individuals and groups to the rigours of objective assessment, in teaching and research.

To blame Monbusho (the Ministry of Education and Culture) is a natural temptation, and is justifiable. But the detail with which the finances of the universities are regulated by people whose allegiance is primarily to the ministry, not the university, is a consequence of Japan's view of the sanctity of public money. Ordinarily, only public servants are allowed to spend it, and then only by a meticulously devised rulebook. Departures from this principle can occasionally cause trouble (see, for example, Nature 372, 579$580 ; 1994)$, but the present intrusiveness of the administrators in Japan's universities thoroughly undermines their cohesiveness. The only good solution would be to reconstitute the national universities as public corporations. That would provide constitutional lawyers with a field-day, but no task is more urgent.

Many of Monbusho's officials are conscious of the need for change, and say so. But in the endless battle between
Tokyo's ministerial bureaucracies, to relinquish control of something is to seem weak. The time has long since passed when Monbusho can hope to win (or even keep) friends by sitting on its hands while the universities it is supposed to nurture are robbed of the effective autonomy they need. $\square$

\section{Chance makes good?}

Britain's national lottery is a bad business, but research should make good use of it while it can.

BRITAIN's month-old national lottery may be elective regressive taxation, taking money from those whose acquaintance with wealth is that they often dream of it (Nature 372, 304; 1994), but it has arrived and should be put to good use. One of its aims is to support good causes, notably charities, culture and the arts. There is some anxiety that this new flow of funds will let the government shrug off many of its present responsibilities, which is one good reason why the British research councils should not go looking for lottery funds. But there are deserving beneficiaries in the scientific world that need not be so choosy.

There is, for example, Burlington House, off London's Piccadilly, which houses (as well as the Royal Academy of Arts) a number of learned societies - the Linnean Society, the Royal Astronomical Society and the Royal Institute of Chemistry, for example. Hitherto, they have lived there rent-free, but they will be expected to bear the costs of maintaining the fabric of their buildings once the government devolves that responsibility to an independent central agency. These societies are charitable, right enough. Their cultural value is also self-evident. Were they so minded, they could make a good case for a rake-off from the lottery. They should not be deterred by the calculation that their interest in science makes them cultural pariahs.

Meanwhile, the lottery has run into controversy (in week three) over a request for anonymity by a man who won a 'jackpot' worth nearly £18 million. At one stage, the lottery organizers won an injunction from the courts to prevent the disclosure by the press of the man's name, but lost it the following day. Since then, there has been a great deal of humbug about press intrusion. But how are the operators, a company called Camelot, to demonstrate that they are doing their job honestly if they keep secret the names of those on whom chance falls? 